University of Pennsylvania Carey Law School

Penn Law: Legal Scholarship Repository

Faculty Scholarship at Penn Law

7-11-2019

\title{
Choice Architecture for Healthier Insurance Choices: Ordering and Partitioning Can Improve Decisions
}

Benedict G.C. Dellaert

Erasmus University Rotterdam

Eric J. Johnson

Columbia Business School

Tom Baker

University of Pennsylvania Carey Law School

Follow this and additional works at: https://scholarship.law.upenn.edu/faculty_scholarship

Part of the Behavioral Economics Commons, Health Economics Commons, Health Law and Policy Commons, and the Insurance Law Commons

\section{Repository Citation}

Dellaert, Benedict G.C.; Johnson, Eric J.; and Baker, Tom, "Choice Architecture for Healthier Insurance Choices: Ordering and Partitioning Can Improve Decisions" (2019). Faculty Scholarship at Penn Law. 2727.

https://scholarship.law.upenn.edu/faculty_scholarship/2727

This Article is brought to you for free and open access by Penn Law: Legal Scholarship Repository. It has been accepted for inclusion in Faculty Scholarship at Penn Law by an authorized administrator of Penn Law: Legal Scholarship Repository. For more information, please contact PennlawIR@law.upenn.edu. 


\title{
Choice Architecture for Healthier Insurance Choices: Ordering and Partitioning Can Improve Decisions
}

\author{
July 12019 \\ Working paper - ERIM - Erasmus University Rotterdam \\ Benedict G.C. Dellaert \\ Erasmus School of Economics, Erasmus University Rotterdam, \\ P.O. Box 1738, 3000 DR Rotterdam, The Netherlands, phone: + 3110408 1301, \\ email: dellaert@ese.eur.nl \\ and \\ Department of Marketing, Monash Business School, Monash University \\ P.O. Box 197, Caulfield East, Victoria 3145, Australia
}

Eric J. Johnson

Columbia Business School, Columbia University, 525 Uris Hall, New York, NY 10027, phone: (212) 854-5068, email: ejj3@columbia.edu

\section{Tom Baker}

University of Pennsylvania Law School, University of Pennsylvania, 3501 Sansom Street, Philadelphia, PA 19104, phone: (215) 746-2185, email: tombaker@law.upenn.edu

\section{Acknowledgments}

We would like to thank Mieke van Os at Independer.nl for providing us with the data used in the field study of this research and for practical insights in the recommendation website's structure, Martijn Willemsen for feedback and support in creating the MouselabWeb icongraphs, and Nuno Camacho for valuable feedback. The first author would like to thank Netspar for financial support for part of this research. The second two authors would like to thank the Alfred E. Sloan Foundation for financial support for part of the research.

\section{Disclosure}

Benedict Dellaert formerly was a member of the independent board of supervisors of Independer. Tom Baker and Eric Johnson are affiliated with Picwell. 


\title{
Choice Architecture for Healthier Insurance Choices: Ordering and Partitioning Can Improve Decisions
}

\begin{abstract}
Health insurance decisions are a challenge for many consumers and influence welfare, health outcomes, and longevity. Two choice architecture tools are examined that can improve these decisions: informed ordering of options (from best to worst) and choice set partitioning. It is hypothesized that these tools can improve choices by changing: (1) decision focus: the options in a set on which consumers focus their attention, and (2) decision strategy: how consumers integrate the different attributes that make up the options. The first experiment focuses on the mediating role of the hypothesized decision processes on consumer decision outcomes. The outcome results are validated further in a field study of over 40,000 consumers making actual health insurance choices and in two additional experiments. The results show that informed ordering and partitioning can reduce consumers' mistakes by hundreds of dollars per year. They suggest that wise choice architecture interventions depend upon two factors: The quality of the user model possessed by the firm to predict consumers' best choice and possible interactions among the ensemble of choice architecture tools.
\end{abstract}

Keywords

Choice architecture, decision-making, consumer decision process, health insurance choice, consumer welfare 
Choice architecture is a potentially powerful way for firms to affect the market behavior of consumers. In this paper, we illustrate these effects in a personally and societally important choice, the selection of health insurance coverage. There is evidence that access to health insurance increases longevity (Woolhandler and Himmelstein 2017). Health insurance decisions are important for consumers because they determine access to potentially lifesaving health care and have important financial consequences. They are important for society because health care coverage is an important contributor to firms' costs and to social justice. Finally, as we shall see, what seem to be minor changes in choice architecture can have a large effect on health insurance product market share and consumer welfare.

Ideally, choice architecture can be used to direct consumers' choices toward better outcomes (Thaler and Sunstein 2008). For example, defaults can be used to facilitate the choice of a good alternative without requiring an extensive contemplation (Johnson and Goldstein 2003). Much research to date has focused on describing the impact of different separate choice architecture tools on consumer choices outcomes (Cadario and Chandon 2018; Johnson et al. 2012; Lamberton and Diehl 2013; Szaszi et al. 2018).

Our goals in this paper are two-fold. Our first goal is to contribute to the understanding of choice architecture. We do this in two ways: One is by exploring the process by which choice architecture changes consumer decision outcomes. We specifically propose and test two types of choice architecture-induced changes in consumer decision processes that affect consumer decision outcomes. The second way is by demonstrating that the quality of the firm's prediction of what is the best choice, what we will call a user model, is an essential component of designing choice architecture.

Our second goal is to demonstrate how a new combination of choice architecture 
interventions can improve health insurance choices. Health insurance choices are highly complex: People often do not understand the basic terms, such as deductibles, used to describe insurance (Loewenstein et al. 2013; Ubel, Comerford, and Johnson 2015), and make mistakes that result in substantial overpayment for coverage (Johnson et al. 2013). A recent examination of the choices of a large firm showed that the majority of decision-makers picked options that were dominated, and employees paid $42 \%$ more ( $\$ 373$ annually) than needed for equivalent coverage (Bhargava, Loewenstein, and Sydnor 2017), essentially wasting a large part of their payments. Improving these choices could both make the allocation of health care resources more efficient for society and improve health outcomes for individuals.

At first blush, improving choices seems close to the idea that marketing should fulfill consumer needs. However, good choice architecture could also lead to the sale of less profitable products. This may be incongruent with the idea that marketing actions should increase profits or shareholder value. Yet, with the rapid advances in large-scale data availability and digital technologies such as artificial intelligence and machine learning, there may be a new reality: Marketers are often be able to predict with great accuracy which products best match a given consumer's needs (Chintagunta, Hanssens, and Hauser 2016) and perhaps they may know better, or as least as well, as a consumer. Therefore, new data-analytics driven services could potentially be designed that use choice architecture to increase the probability consumers will choose the product that is best for them, and at the same time may provide new business opportunities for firms. Domains such as health, consumer finance, and education, are especially promising for such interventions, because they involve high-impact consumer decisions, where the complexity of the decision makes it difficult for consumers to select the best available option by themselves. We return to how this may affect firm market shares and consumer welfare, in 
the short and long term at the end of this paper.

\section{Choice Architecture Processes: Decision Focus and Decision Strategy}

To intelligently choose and implement choice architecture interventions, marketers need to understand how the intervention affects consumers' decision making. There has been significant research examining the way that preselecting options, or default effects work (Carroll et al. 2009; Dinner et al. 2011; Jachimowicz et al. 2017). The robustness of default effects may be due to multiple causes, including the ease of selecting the default, the implied endorsement of the default, and the fact that the default option might be seen as an endowed option (Brown and Krishna 2004). However, there are many other elements of choice architecture, such as ordering, partitioning, deciding the size of a choice set, and the labeling of attributes that have seen less exploration of the mechanisms that determine their effectiveness.

We concentrate on two decision process mechanisms that apply across several different interventions but seem particularly relevant to the choice architecture interventions we examine: partitioning the choice set and ordering the choice set by predicted quality. The first mechanism is that choice architecture can change the options examined by consumers. Decision-makers allocate attention differentially across options, and choice architecture can change this allocation to shift attention towards the highest quality options. We term this mechanism decision focus. Imagine, for example, that a consumer inspects only the first five options, even when the total set of products is much larger. If the choice architect changes the order presented to the consumer, this will change the alternatives the consumer considers and, perhaps, the alternative chosen. The second mechanism is that choice architecture can change the way consumers process the attributes that describe the options. We term this consumers' decision strategy. One well-known 
taxonomy used to describe strategies differentiates between compensatory and noncompensatory heuristics (Gilbride and Allenby 2004; Payne, Bettman, and Johnson 1993). Roughly speaking, compensatory strategies are more effortful, and make tradeoffs between attributes, while non-compensatory strategies are simpler, because they do not directly make tradeoffs. Although there are cases where non-compensatory strategies produce good choices, non-compensatory strategies can perform badly if here is a negative correlation between the attributes of the options (Bettman et al. 1993). This occurs frequently, for example because of physical and financial constraints. Insurance policies with low premiums must have higher deductibles to be viable, and gasoline vehicles with great acceleration tend to have worse fuel economy. More generally, markets in which all products are on the efficient frontier will be constrained to have some negatively correlated attributes (Johnson and Payne, 1985). As a result, choice architecture that encourages non-compensatory strategies can, in some cases, produce worse choices. To discuss how these two decision processes may be influenced by choice architecture, we turn to our two common interventions, often used in practice, but that have received less academic attention, partitioning and ordering.

\section{Partitioning Effects on Decision Focus and Strategy}

Partitioning (Cheema and Soman 2008; Dorn, Messner, and Wänke 2016; Johnson et al. 2012) separates a choice set into two or more sets that can be inspected sequentially. Many web sites present a "soft" partitioning that allows consumers to easily click through from a first, smaller selection to the another, larger selection of options. For example, an airline site might first present a small subset of all possible flights. Doing this draws decision makers' attention to the initially presented products (which we call the primary set), but at the same time allows them 
the option to click through to see the remainder of the set (i.e., the full set). Through

partitioning, the initial inspection for the first presented set of alternatives is less costly (in terms of effort) to the consumer than inspection of the full set (which requires one or more additional information requests, such as a mouse click).

Normatively, given that the additional costs (one mouse click) of accessing the full set are negligible, inspection of the full set might have a positive return for the consumer and, therefore, consumers should typically continue to inspect this set after inspecting the primary set. In contrast, we predict that decision makers are myopic and that the perceptually more prominent, higher cost of having to click through to the next screen will dominate the potential returns to search in consumers' decisions to inspect the full set or not (Häubl, Dellaert, and Donkers 2010; Hogarth and Einhorn 1992; Wilson et al. 2000). This suggests that partitioning will increase consumers' focus on the smaller restricted set of alternatives.

Evidence also suggests that this reduction may affect the consumer's decision strategy. Typically, when faced with a large choice set, consumers make first make a less detailed evaluation of the larger set of alternatives followed by a more in-depth comparison takes for a small subset of products (Chakravarti, Janiszewski, and Ülkümen 2006; Payne 1976). While compensatory strategies may not be cognitively feasible in a making a decision for the full set (Besedeš et al. 2015; Chernev, Böckenholt, and Goodman 2015; Dellaert and Häubl 2012; Hanoch et al. 2011), presenting a smaller primary set will increase the probability of consumers using a compensatory decision strategy, promoting tradeoffs between different attributes (Johnson and Meyer 1984; Payne, Bettman, and Johnson 1993). In contrast, when choice sets are large, heuristics such as screening will cause consumers to focus on one attribute, which increases its weight and lowers decision quality. 


\section{Ordering Effects on Decision Focus and Strategy}

The second intervention we examine involves ordering the options. If options presented early in a choice set have an advantage in being chosen, then populating these positions with alternatives most likely to be good for the consumer may improve choice. The basic idea is that order effects should be used to the consumers' advantage.

There is a large and complex literature that examines the effect of option order which has a complex set of results. In some studies, people demonstrate edge avoidance and concentrate on options occupying the center of the visual field (Atalay, Bodur, and Rasolofoarison 2012), but in many other studies there seems to be an advantage of being first, with some usually smaller advantage of being last (Bar-Hillel 2015). One way of reconciling this discrepancy is to suggest that it is not order, per se, that produces order effects, but rather attention is the key factor in mediating the advantage of order. For example, Atalay et al. (2012) find that attention mediates the effect of order and other studies which control order by serial presentation of stimuli show strong advantages of being first (Mantonakis, et al. 2009; Russo, Carlson, and Meloy, 2006). Other applications that show strong advantages of choices from ordered lists include an increase in the downloads of working papers by economists (Feenberg et al. 2017) and the vote share of political candidates (Koppell and Steen 2004; Miller and Krosnick 1998), although in the case of voting there are moderating variables (Ho and Imai 2008). Our concept of decision focus captures the idea that increased attention can lead to significant advantages in choice. We argue, therefore that for a list of options (as opposed to a matrix that features pictorial information), the 
first options will receive increased attention. ${ }^{1}$

In contrast to the effect of focus, the effect of ordered lists on decision strategy is less clear. Because ordering does not change the number and type of the options that are in the choice set, and may even increase the complexity of comparing between options by bringing more similar options closer together, we may not see a shift to compensatory strategies. In addition, there is evidence that in some settings the effects of ordering by attractiveness is not helpful to consumers (Diehl 2005). In this case, ironically, consumers search, too much. This over-search can lead to worse choice outcomes, because it is more challenging for consumers to select the best option from a larger set of options, which makes it more likely they choose a less attractive one. In sum, we hypothesize that order could increase focus on desirable options, but suspect that effects on strategy may be negligible or even negative.

\section{User Models and Choice Architecture}

The effectiveness of both partitioning and ordering depends strongly on how well the choice architect can predict what is the best choice for the consumer. But given its importance, it is surprising that the quality of this understanding, which we refer to as a user model, has not received more explicit attention. For example, if the designer is naïve about what people need, the subset provided by the partition might not contain better options, and the ordering could be unrelated to choice quality. The accuracy of a user model will determine whether ordering is helpful, has no effect, or even is potentially harmful.

\footnotetext{
${ }^{1}$ We distinguish this from applications that sort options by a single attribute. Every choice set has an order, even if it is random. Contrast this to applications that sort by price or quality (Lynch and Ariely 2000; Suk, Lee, and Lichtenstein 2012). That literature shows that sorting on an attribute increases the importance of the attribute and leads individuals to eliminate based on that attribute. Sorting by predicted quality, should increase, via reading order, of the choice of the first options.
} 
User models can differ in quality for at least two reasons: First, the marketer may not know what is best for, or desired by, consumers. Some user models' predictions are relatively accurate and uncontroversial. For example, most people undersave for retirement, would like to save more, and usually endorse the use of choice architecture tools such as defaults to increase their savings (Madrian et al. 2017; Thaler and Benartzi 2004). Similarly, many individuals are not very physically active, would like to exercise more, and support the use of choice architecture to promote going to the gym more often (Milkman, Milson, and Volpp 2013). The second reason why the user model might be inaccurate for any individual consumer is that consumers needs and tastes might differ, and the firm may be unable to predict those differences. Unobservable heterogeneity across consumers represent a challenge to choice architecture.

The quality of the user model will moderate the impact of most if not all choice architecture interventions. User models can differ on several dimensions: They may be based on normative models, use simple notions like ranking by market share, or use complex recommender systems. But in all cases, user model quality is essential to implementing choice architecture in the consumer's best interest. Defaults, for example, presume that the firm knows what is in the best interest of customers.

What should be done when user models are inaccurate? In these cases, strong choice architecture might not improve the quality of choice or can even lead to a decrease in decision quality. When user model quality is low, a choice architecture that supports greater consumer autonomy could be more beneficial for consumers. Variability in the quality of user models raises, therefore, an important question for choice architects: How to facilitate and improve consumer choice while preserving consumer autonomy? 


\section{Hypotheses}

In sum, we propose two choice architecture tools that can, in principle, improve choice: (1) partitioning large sets into two sets: a primary set of only a small number of alternatives and a secondary set consisting of all the other alternatives, and (2) ordering options by a user model. We argue that both of these interventions affect the decision focus of choosers and that partitioning can affect consumer's strategies in a positive manner. Finally, the quality of the user model will determine if partitioning and ordering might help or hurt choice.

Both partitioning and ordering are relatively "soft" interventions: They do not remove options from the choice set or marketplace, but we hypothesize that these (soft) restriction improves consumer choice outcomes because they encourage consumers' decision focus to better alternatives and change consumer strategies by encouraging a more compensatory decision strategy that takes into account more of the relevant attributes.

Given that partitioning, ordering, and user models may individually and together affect choice outcomes, we now turn to develop a set of hypotheses that capture these effects. Our contribution is to show that both partitioning and ordering can aid choices, but only in the presence of an accurate user model. Further, we show that these effects are due to shifts in decision focus and strategy, even when the choice architecture interventions involve relatively small and normatively irrelevant changes in the display.

H1: Partitioning affects decision strategy. Because partitioning reduces the number of immediately visible options, we expect a shift to compensatory strategies.

H2: Informed ordering affects decision focus. The effects of ordering suggest that the best options will receive more attention when an ordering benefits from a more accurate user model. We term an ordering that uses a more accurate user model an informed ordering and 
predict that, compared to a nä̈ve (i.e., more random) ordering, it will increase decision focus because the best options are presented at the top of the list. However, because the number of options remain unchanged and ordering promotes greater closeness of attractiveness we expect little change in strategy.

H3: Partitioning affects decision focus, but only with informed ordering. Although the remainder of options are only one click away and can contain the most favorable options, we expect partitioning to cause individuals to focus attention on the smaller recommended set. This focus contrasts with an analysis that suggests that search would be driven by the attractiveness of the yet-to-be-inspected options. The relatively small additional cost will loom large in allocations of attention. When ordering is informed (i.e., based on a high-quality user model), this smaller recommended set supports decision focus on the best options. However, when ordering is naïve, consumer attention will be focused on a random set of options, and decision focus on the best options is likely to deteriorate.

H4: Partitioning improves choice with informed ordering but worsens choice with naïve ordering. Because the smaller set in the partitioning is more likely to contain the better options, the combination of an informed ordering with partitioning will improve choice. This improvement is stronger than the sum of the separate impact that partitioning and ordering can produce. In other words, partitioning and informed ordering interact to produce an even greater improvement in choice. In contrast, partitioning combined with a naïve ordering can be harmful to consumer choice. In our experiments, the naïve ordering is close to random, but we would expect a greater decrease in choice quality if the user model generated a perverse ordering whereby order was negatively correlated with what is best for consumers. 
H5: Changes in decision strategy and focus mediate this improvement. More precisely, we predict that consumer choice outcomes will change due to shifts in the two consumer decision processes and that these decision processes, in turn, are impacted by the choice architecture interventions that are introduced. These effects represent a parallel mediation process, as visualized in Figure 1. Thus, we hypothesize, first, that consumers' use of compensatory decision strategies mediates the effect of partitioning on consumer decision outcomes, and second, that consumers' focus on the best alternatives mediates the impact of an informed ordering on consumer decision outcomes. Third, we also predict that the informed ordering will moderate the effect of partitioning on consumer decision outcomes and that this improvement will be mediated by consumers' focus on the best alternatives (mediated moderation). Figure 1 represents our hypotheses.

- INSERT FIGURE 1 ABOUT HERE -

\section{Study 1: Consumer Health Insurance Choice with Ordered and Partitioned Sets}

In Study 1, we investigated the hypothesized effects of ordering and partitioning on consumers' choice outcomes and decision processes. We constructed a choice task modeled on a typical consumer decision task on health insurance exchange websites that allow consumers to purchase health insurance plans. The website was similar in many ways to HealthCare.gov and the other health insurance exchange websites established under the Affordable Care Act in the United States (Wong et al. 2016). We manipulated two components: (1) the quality of the user model, based on which products were ordered in the set (low quality model for a naïve ordering 
versus a high quality model for an informed ordering), and (2) the absence or presence of partitioning in the ordered set. Note that the quality of the user model was reflected in the quality of the ordering. These two aspects work closely in tandem: user model quality is presented to consumers through ordering.

The participants were given a defined goal representing the utility of another person and asked to follow this clearly defined decision rule. The rule stated that their objective was to minimize total expected costs given the person's health care needs usage and the three provided attributes. This eliminated unobserved preference heterogeneity between participants allowing us to objectively define the quality of the decision that each participant made. We also investigated how consumers' decision processes change based on ordering, partitioning, and their interaction. To do so, we used a MouselabWEB interface that allowed us to directly observe which product attribute levels participants inspected during their decision process, and in which order (see www.mouselabweb.org). This technique has been shown to be useful in the study of individual choice, as well as games and time preferences (Costa-Gomes and Crawford 2006; Gabaix et al. 2006; Payne, Bettman, and Johnson 1993; Willemsen and Johnson 2011).

\section{Method}

This study was a framed-field experiment (Harrison and List 2004) where actual decision-makers made decisions with realistic stimuli. To increase the stakes, participants received a monetary reward based on their performance in the task. More specifically, they received \$2 for participating and could earn an additional bonus of up to \$6 dollars depending on how well their choices matched the assigned goals. Participants were randomly assigned to one 
of four treatment conditions, based on a 2 (ordering: informed vs. naïve) by 2 (partitioning: yes vs. no) between-subjects experimental design. All conditions presented the same eight health insurance plans. The choice task was repeated once for each participant under the same experimental condition, but with different attribute values. Under the informed ordering condition, alternatives were ordered almost perfectly in order from best to worse (according to the participants' decision rule of minimizing expected costs). The only deviation was that the first and third alternatives were switched. The naïve ordering condition presented a randomized order of alternatives to participants with one exception, which was that the best alternative was placed in the fourth ranked position. In the partitioned condition, respondents were shown the first three recommended products, with the easily visible option of clicking through to the complete list. The non-partitioned condition showed the complete ordered list of all the recommended products directly to the participants (see Web Appendix A.1 for illustrations of the two partitioning conditions).

Health insurance plans were described in terms of three key characteristics for the U.S. market - the monthly premium, the doctor visit copayment, and the annual deductible. These were also successfully used in earlier research in this domain and market (Bhargava et al. 2017; Johnson et al. 2013). The plans reflected a realistic product set in the participants' health insurance market. The participants were also given the relevant health care usage of the person for whom they were making the choice. This information allowed them to calculate the annual expected costs of each of the health insurance products presented in the recommendation list.

To obtain deeper insight into the participants' decision process while selecting an alternative from the list, we implemented the experiment with a MouselabWEB online interface (Willemsen and Johnson 2011). MouselabWEB allows researchers to trace the content and 
sequence of decision processes. The participants viewed a table in which each row represented a different health plan and each column displayed a different plan attribute. This format corresponded with the how recommendation lists are typically presented to participants on health insurance exchange websites. In the MouselabWEB interface, participants used their mouse to move the pointer on the screen across the different boxes in the table representing the different attributes of each alternative. When the pointer hovers over a box, the level (value) of the respective attribute is revealed, and when the pointer is moved, the information is hidden. This process reveals how often, for how long, and in which order participants examined the information about the attributes of each plan. Past research suggests a close correlation between MouselabWEB observations and eye-tracking data, which can be an alternative way of tracing participants' decision processes (Lohse and Johnson 1996; Reisen, Hoffrage, and Mast 2008). These data provide deep insight into the process behind the participants' decision making. We used the MouselabWEB data to investigate differences in participants' decision processes depending on whether or not they were presented with different combinations of ordering and partitioning. These differences can reveal if the hypothesized shifts in decision making process explain the effects of ordering and partitioning in improving consumer decision outcomes.

The participants were recruited through Amazon MTurk using US participants. We predetermined the sample size to be 200 per treatment condition, almost twice that used in a similar paradigm (Johnson et al. 2013). The assignment to treatment conditions was randomized and the data collection was stopped after all the conditions contained at least 200 observations. A total of 846 responses were obtained, and 18 outliers were eliminated because they had made extraordinarily few (less than four) or many (more than 600) information acquisitions during the choice process. The average age of the participants in the sample was 34.5 years old, $43.6 \%$ 
were female, and 50.3\% had obtained a bachelor's or higher degree.

The order of our description of the results maps into the hypotheses in Figure 1. We first examine if the changes in choice architecture change the type of decision processing used by the participants (H1 to $\mathrm{H} 3$ ). We then move to the right side of the figure to examine the effect of choice architecture on the choices made by respondents (H4). We relate the two by testing for mediated moderation of the decision process on choice outcomes (H5).

\section{Results: Process Data}

First, we studied the process-level data obtained from the MouselabWEB interface. This interface allowed us to directly observe which product attribute levels participants inspected during their decision process and in which order. We find strong effects of the interventions on the decision processes, with partitioning changing decision strategy, and partitioning combined with informed ordering producing an increase in decision focus.

We first present the data visually, in Figure 2, summarizing these data graphically in four icon graphs (Willemsen and Johnson 2011), each representing one of the four experimental conditions. The icon graphs summarize participants' information acquisition processes. Each box corresponds to one of the cells in the displays shown to respondents. For example, the top left box in the upper left panel represents the monthly premium of Plan A in the non-partitioned, naïve ordering condition. The length of the box represents the average time participants spent inspecting a value (e.g., seven seconds) and the height represents the average number of times participants acquired that value (e.g., three times). The length of the arrows between the boxes represents the number of transitions participants made in their information acquisition process (e.g., seven horizontal transitions from the monthly premium in plan A to the doctor visit copay 
also in plan A). The results are the means within each experimental condition for the two repeated choice tasks. The inspection levels and large number of transitions show a significant amount of interest by the participants, who on average took 92.6 seconds to make each choice. Following standard practice, we eliminated all information acquisition observations of $200 \mathrm{~ms}$ or less, because they were too short to be seen by the participants and probably reflect movements of the pointer from one cell to the next (Willemsen and Johnson 2011).

\section{- INSERT FIGURES 2, 3, AND 4 ABOUT HERE -}

The figure clearly shows the effects of partitioning and ordering on the decision processes, which can be observed by comparing the panels representing the different experimental conditions. To conduct statistical tests of these effects, we constructed two process variables corresponding to the hypothesized processes based on the inspection data. First, decision strategy was measured using the Payne (1976) index measure. The Payne index (PI) captures whether a participant's information acquisition process is more alternative-based or attribute-based. Alternative-based information acquisition reflects a compensatory decision making process. The $P I$ takes the ratio of the difference between the number of alternative-based (horizontal) acquisition steps (NrALT) and the number of attribute-based acquisition steps (NrATT) and the sum of these two types of information acquisition steps, all from the MouselabWEB data $(P I=(N r A L T-N r A T T) /(N r A L T+N r A T T)$. A score of 1 represents a completely alternative-based decision process (reflects a compensatory decision strategy), and a score of - 1 represents a completely attribute-based search (reflects a non-compensatory decision strategy). Second, decision focus was measured by the proportion of time spent inspecting the best three alternatives (i.e., those with the lowest total cost in the defined utility task), relative to 
total time looking at alternatives, with zero being no focus and 1 being total focus (in the mediation analysis, we take the natural log of this value).

Figure 3 presents the average scores of the process variables by experimental condition. We ran analyses of variance to test for the significance of these results with partitioning, informed ordering, and their interaction as explanatory variables. Panel A shows the Payne Index as our decision strategy measure. As hypothesized, partitioning leads to an increased use of compensatory decision strategies, indicated by the relatively more positive means in the figure. $(\mathrm{H} 1 ; \mathrm{F}(1,1643)=19.7, \mathrm{p}<.001)$. In addition there is a much smaller unpredicted effect, which is that informed ordering leads to a less compensatory decision process $(F(1,1643)=4.5$, $\mathrm{p}<.05$ ). Panel B shows the result for decision focus. As hypothesized, we find that informed ordering strongly increases decision focus $(\mathrm{H} 2 ; \mathrm{F}(1,1643)=2390.6, \mathrm{p}<.001)$. Also as hypothesized, the interaction of partitioning and ordering was significant: partitioning leads to an increase in decision focus (i.e., a greater ratio of time spent inspecting the best three options) with informed ordering, but to a decrease in decision focus with naïve ordering $(\mathrm{H} 3 ; \mathrm{F}(1,1643)=$ 1062.7, $\mathrm{p}<.001)$.

\section{Results: Choice Outcomes}

Next, we investigated the hypothesized combined effect of ordering and partitioning on consumer choice (H4). We analyzed (1) the probability that a participant selected the best alternative as a function of condition, and also the complementary dependent variable of (2) how much each participant overpaid as a result of selecting a suboptimal product in each condition. Both variables reflect deviations from the best insurance product specified by the decision rule communicated to the participants (Johnson et al. 2013). Figure 4 (panel A) presents the accuracy 
of choice, using the percentage of consumers choosing the best product under each condition (the upper bars in the figure) and the excess payment in dollars (the lower bars in the figure), both averaged over the two choices per participant. Having an informed ordering positively impacts on both measures, while partitioning clearly interacts with the kind of ordering, helping with informed ordering and hurting with the naïve ordering. A random effects logistic model for the choice of the best option confirmed these effects. The model analyzed if the best option was chosen using the effects of ordering, partitioning, and their interaction. The results support the hypothesized positive impact of partitioning with informed ordering, and that this impact reverses with naïve ordering. A random effects regression model for the excess amount participants paid also showed a strong significant interaction of ordering and partitioning in the predicted direction (see Web Appendix B.1 for the detailed estimation results for both models).

\section{Results: Mediation Analysis}

Why do partitioning and informed ordering improve choices? To test the hypothesized mediated moderation structure of decision strategy and decision focus on choice outcome (see Figure 1), we conducted analyses using Hayes' (2013) PROCESS module in SPSS. We analyzed as our key dependent variable whether or not participants had made the best choice. Ordering (informed, naïve), partitioning (yes, no), and their interaction were the main independent variables. The mediating process variables decision strategy (i.e., the Payne index) and decision focus (i.e., relative time spent on best options) were also included, as was the anticipated moderating effect of ordering on the effect of partitioning on decision focus. In the model estimation, we used the data on the two observations per participant and included an order variable as a covariate. The results of the analyses are presented in Table 1. Following the 
procedure outlined in Zhao, Lynch, and Chen (2010), the table first reports the unstandardized coefficients for the different pathways in the model. These include the anticipated effects of ordering and partitioning on the mediating variables decision strategy and focus. Consistent with our prior analysis, we find support for $\mathrm{H} 1, \mathrm{H} 2$ and $\mathrm{H} 3$, the effects of the manipulations on the hypothesized decision processes. We also find support for the anticipated effects of the two decision processes on the dependent variable of choosing the best option.

Most importantly, the analysis allows us to look at the indirect effects of ordering and partitioning on the decision outcome, via the two parallel mediating decision processes. In Table 1 , these results are shown in the bottom part with the $95 \%$ confidence intervals from the bootstrap analysis. If these confidence intervals are significantly different from zero, there is support for the mediation hypothesis H5. First, we concentrate on the mediation of the effects via of decision strategy. The results show that decision strategy indeed serves as a mediator of the effect of partitioning on the choice of the best alternative (see the two rows for Indirect Effect of Decision Strategy; $\mathrm{p}<.05$ ). Next, we look at the mediation via decision focus. We find decision focus is a significant mediator of the effect of partitioning on the dependent variable (see the two rows for Indirect Effect of Decision Focus; $\mathrm{p}<.05$ ). Finally, we find that the moderating effect of informed ordering on partitioning is also mediated by decision focus as hypothesized (see the row for Moderating Effect of Informed Ordering on Indirect Effect of Decision Focus; $\mathrm{p}<.05)$. Jointly, these mediating effects provide strong support for H5.

- INSERT TABLE 1 ABOUT HERE -

\section{Discussion}

The results of Study 1 provide outcome- as well as process-level support for the hypothesized impact of ordering and partitioning on consumer choice in an incentive-compatible 
decision-making setting with objectively defined different utility levels between the different choice outcomes. In terms of decision outcomes, the results strongly support H4. We find that informed ordering is beneficial for consumers and that partitioning is also beneficial when combined with informed ordering, but not when ordering is naïve. In terms of decision process, the MouselabWEB data-based analysis allowed us to test $\mathrm{H} 1$ to $\mathrm{H} 3$ and H5. The results supported our hypotheses and showed that the impact of ordering and partitioning on choice outcomes is mediated by participants' use of a more compensatory decision making process (decision strategy) and their increased focus on the best alternatives (decision focus). These findings show that partitioning combined with informed ordering based on a high-quality user model (e.g., ordering based on the product's overall attractiveness to the consumer) constitutes a choice architecture ensemble that is beneficial for consumers. However, with a naïve ordering (when user model quality is low), partitioning can harm consumers, particularly by shifting their attention to less attractive options in the set.

\section{Study 2: Field Study of a Health Insurance Choice Architecture Redesign}

Study 1 showed that partitioning and ordering can improve choice in a framed field experiment, but that does not ensure that similar results would occur in a real insurance marketplace. In particular, we were concerned that actual buyers may not respond the same way in a real-world environment and that the results may be limited to the artificial MouselabWEB environment which is devoid of logos and may place restrictions on non-focal visual search. Finally, perhaps the effects of partitioning may disappear if consumers make consequential choices costing consumers significant money. Therefore, in Study 2 we analyzed field data from 
a leading financial product comparison website in the Netherlands. The website is similar in many respects to HealthCare.gov in the United States and other health insurance exchange websites (Wong et al. 2016). The firm serves as an intermediary between consumers and suppliers of health insurance. Health insurance plans can be purchased directly through the website and many consumers go to the site each year to switch insurance providers. The data we obtained comes from a quasi-experiment involving a major interface redesign. The firm introduced an informed ordering and partitioning intervention into their personalized health insurance recommendation lists. By comparing consumer insurance choice data before and after the interface redesign, we can examine the impact of this particular ordering and partitioning intervention and see whether the results in a real-world environment are consistent with our outcome-oriented hypothesis $\mathrm{H} 4$ that informed ordering and partitioning improve consumer choice outcomes (Ericson and Starc 2012).

\section{Data}

Users of the website entered their personal characteristics and desired insurance specifications, including whether they would like additional coverage above the legal minimum. Based on this information, they were presented with an ordered list of recommended health insurance alternatives. The original choice architecture was a full recommendation list of health insurance products that met each consumer's prespecified criteria, ordered from low to high according to the premium (i.e., the plan's purchase price) and displayed in groups of 10 to fit on a webpage. After the redesign, the recommendation list was partitioned in two sections that reflected an improved user model that reflect both price and quality. The first section presented 
the top three most highly recommended products, ordered according to the model (see Web Appendix A.2 for before and after design). The firm introduced the new price-quality ordering to more closely correspond to user preferences and better reflect consumer interests than the prior ordering based only on price. In our terms, they improved their user model to produce a more informed ordering reflecting the fact that consumers must make tradeoffs between these attributes that are often negatively correlated. The redesign also introduced a partitioning: Presenting a subset of the three plans highest ranked by the user model, but consumers could choose to click through to inspect the full list of 10 health insurance products. ${ }^{2}$ Thus, the redesign corresponded to a move from a non-partitioned, more naïve ordering, to a partitioned, more informed ordering.

Consumers were able to purchase the insurance directly via the recommendation website for most products. For a subset of products, they had to visit the insurer's website to make the purchase. In the latter case, we were not able to observe whether a policy was purchased with the insurance company or if they were only browsing. Therefore, we only analyzed visits in which consumers made purchases directly through the recommendation website. This allowed us to track the impact of changes in the website choice architecture on consumers' actual market choices.

We obtained data from November to December of two consecutive years, Year 1 (before the website choice architecture redesign) and from November to December of Year 2 (after the website choice architecture redesign). Almost all health insurance purchases are made in the

\footnotetext{
${ }^{2}$ The consumers could choose to sort this full list based on a product criterion that they selected, with price-based ordering being the default in the full list presentation. As an intermediate step, the consumers were automatically shown the lowest price alternative if this was not already part of the top three price-quality ranking. This step provided additional information in the recommended set to some consumers in the sample.
} 
Netherlands during these two months, because this is the open enrollment period set by law. In the data, health insurance products were purchased on the website during a total of 8,519 visits in Year 1 and during 35,113 visits in Year 2. The website introduced a significant marketing campaign along with the redesign, likely attracting, along with the redesign, many more consumers to the website than before the change. Because of privacy concerns, we were only able to obtain consumers' age for the two years as sociodemographic background variables. In Year 1, the average age was 36.2 years, and in Year 2 it was 39.1 years. For both Year 1 and Year 2, the data we obtained captured the first 10 alternatives presented in the recommendation list. Very few consumers chose outside of the first 10 alternatives and, hence, no other alternatives were stored by the website. In Year 1, the data represented the full first page of recommended products, and in Year 2 the data covered the top three products first presented to consumers and the subsequent page that they could click through, with the first 10 alternatives. We also obtained the rank position of each alternative, as well as the user's individual characteristics and insurance specifications and, finally, the alternative that was purchased.

\section{Results}

Figure 5 provides an overview of the results from the field study. In Year 1 (no partitioning, price-only ordering), we found that $47.6 \%$ of the visitors who bought health insurance selected the first-ranked alternative. In Year 2 (partitioning, price-quality based ordering), $60.8 \%$ of the visitors who bought health insurance selected the first-ranked alternative. More remarkably, the share of the lowest-ranked options in positions 4-10 declined from 31.2\% to $12.8 \%$, a decrease of $59 \%$ in relative market share, due, in part to the introduction of a soft partition with only one click added. 
To test the impact of the introduction of the new choice architecture design on the rank of the products that the consumer purchased between the years, we estimated an ordered probit model. The ordered probit is most appropriate for this analysis because it takes into account the fact that, although a higher-ranked position is superior to a lower-ranked one, we cannot observe the metric distance in attractiveness between the ranks. It allows us to take into account the rank-order information from all consumers. The results of the ordered probit analysis strongly support the hypothesized positive combined effect of informed ordering and partitioning on consumer choice outcomes. We find the new choice architecture design has a significant effect in the expected direction $(\beta=.67, p<.001)$. This effect shows that, after the introduction of the new choice architecture, consumers were significantly more likely to choose a higher-ranked alternative. As a robustness check, we also estimated the ordered probit model while controlling for participants' age. The effect of this control variable was significant $(\beta=-.01 ; p=0.001)$ indicating that overall, older consumers were less likely to choose a higher ranked alternative. Adding this control variable to the model did not affect the significance of the other results.

\section{- INSERT FIGURE 5 ABOUT HERE -}

\section{Discussion}

The results of the field study provide real-world validation of the possible changes in choice that we predict when an informed order is combined with partitioning. We found that consumers made different choices in the non-partitioned price-only based ordering setting compared to the new choice architecture design and the results of the ordered probit model estimates revealed a strong positive effect of introducing the new design. Of course, this study is limited since there are a number of other factors that were not controlled when the intervention 
occurred, such as the presence of different customers, new policies, and policy characteristics, a limitation we address with Study 3.

\section{Study 3: Experimentally Controlled Lab Replication of the Field Study}

Because the field data reflect real-world conditions, one potential confounding effect was the fact that the website likely attracted a broader, less expert, consumer segment to the redesigned website than before the change and it is unknown how that may have affected the decisions we observed. Also, because the recommendations were personalized, we cannot rule out the possibility that differences in the composition of recommendation lists could also have affected the responses to the partitioned recommendations. Therefore, in Study 3, we replicated the field study result in a simplified controlled online study that assigned respondents randomly to treatment conditions and presented the same set of alternatives to all respondents.

\section{Method}

The participants were randomly assigned to one of four treatment conditions in a 2 (ordering: informed vs. uninformed) x 2 (partitioning: yes vs. no) between-subjects experimental design. In all conditions, participants were presented with a recommendation list of 10 health insurance plans (see Web Appendix A.3). The plans were ordered on one of two measures of attractiveness: a more informed comprehensive measure that combined both price and quality based on the firm's expert evaluations (ordered from the most to the least attractive price-quality score as was done in the field study), and a naïve ordering based on price only (ordered from the most to the least attractive price). We also varied whether or not the set was partitioned: The partitioned condition showed participants the three most highly recommended products, with the 
option to click through to the full list (ranked on the same ordering criterion). The full recommendation list condition showed the ordered list of all recommended products directly to the participants without partitioning. The products were described in terms of the key health insurance product features used on the health insurance comparison website from which we obtained our field data. The participants could click on a help link to see a short explanation of each feature. Although the presence of partitioning and the order of presentation varied, the participants had access to the exact same set of products and explanations under all conditions; therefore, any changes in observed choices must be due to the manipulated factors.

The participants were asked to make a choice from the health insurance plans presented as if they had to select a health insurance plan for themselves. The plans on the recommendation list closely reflected a realistic product selection in the participants' health insurance market (the Netherlands) for adults. The actual plans and price-quality ordering were taken from the website from which we obtained the field data for Study 2. The brand names were changed to fictitious ones to avoid unobserved brand associations that the participants could have. The only minor modifications made were to avoid the presence of clearly dominating alternatives in the list. For this study, a total of 858 participants over the age of 18 were recruited through a large-scale online panel run by a marketing research company. The average age of the participants was 46.7 years old, $50.9 \%$ of them were female, $36.9 \%$ had a bachelor's or higher degree, and $38.7 \%$ had bought health insurance for themselves or someone else in their household within the past two years. 


\section{Results}

To determine the significance of the observed differences in the ranks chosen between the conditions, we used an ordered probit model, as in the field study, to analyze the effects of a naïve ordering (based on price-only) versus an informed ordering ( based on price and quality), partitioning, and the interaction between these two factors The results of the analysis strongly support the results of the field study. We find that informed ordering and partitioning made consumers more likely to choose higher ranked options, with significant positive effects of informed ordering $(\beta=.80, p<.001)$ and partitioning $(\beta=1.83, p<.001)$ as expected. We find no significant interaction of informed ordering and partitioning $(\beta=.12, p=.33)$. As a robustness check, we also estimated the ordered probit model while controlling for the participants' experience with buying health insurance in the past two years (yes/no). The effect of this control variable was not significant, and adding it to the model did not affect the significance of the other results.

\section{Discussion}

The results of this study replicated that informed ordering and partitioning improve health care plan choices. Unlike Study 2, which used a quasi-experimental design that limits inferences of causality, Study 3 demonstrated in a controlled experiment that informed ordering and partitioning cause improvements in choices between health care plans. In contrast to Study 1, we do not find a significant interaction between ordering and partitioning. This can perhaps be explained by the fact that a price-based ordering is still informative to consumers which may have attenuated the negative impact of the naïve ordering condition. We investigate the effect of a partially informed ordering on consumer choice outcomes in Study 4. 


\section{Study 4: Partitioning Improves Consumer Choice Outcomes under Moderately Informed Ordering as Well}

Study 4 extends our work to a setting with a more realistic, partially informed ordering. This allows us to assess the impact of ordering and partitioning under more realistic conditions where the firm might have a moderately noisy ordering of options that would arise from an imperfect, but informative user model. We used the same Dutch-language website as the basis for the experiment, introducing an additional third, moderately informed ordering. As in Study 1, the experiment employed a defined utility task that instructed participants which tradeoff to optimize in selecting an alternative from the set, but without incentives. This again allowed us to define an objectively best option in the choice task.

\section{Method}

The participants were randomly assigned to one of the six treatment conditions of a 3 (ordering: informed, partially informed, naïve) x 2 (partitioning: yes vs. no) between-subjects experimental design. In all conditions, participants were presented with a list of the same 10 health insurance plans. The participants responded to a defined utility task in which they were asked to choose from the health insurance plans presented to them as if they were choosing a plan on behalf of a person they knew well but who was not part of their own household (e.g., an

elderly aunt or uncle). They were told that this person desired a minimum (well-defined) level of coverage and, otherwise, to choose the best buy. The best buy was defined for them as the highest ratio of the monthly premium paid and the review ratings that customers gave the insurance provider. Since they were based on the real-world website in Study 2, the plans reflect a realistic product set in the participants' health insurance market (the Netherlands). We 
changed the brand names to be fictitious and participants could click on a help link to see a short explanation of each attribute.

Under the informed ordering condition, alternatives were ordered to be almost perfectly aligned with the predefined decision criterion. The only deviation was that the third and fourth alternatives in the ranking were reversed. The partially informed ordering reversed the position of the first and third alternatives. This condition examined if a top-three partitioning could help increase consumers' ability to select the best alternative, even when the ordering was noisy. The naïve ordering condition randomized the options, with two constraints: first, the third-ranked alternative was kept identical to that in the informed ordering condition, allowing us to more clearly compare the consumer choices between the three conditions. Second, the most attractive alternative was fifth, so that the participants would have to search beyond the partitioning to find the best alternative in the list.

We used two partitioning conditions, a non-partitioned condition and a partitioned condition presenting the first three recommended products with a prominent button allowing them to click through to the full list. The full list condition showed the ordered set of all the recommended products directly to the participants. This structure was the same as in Study 3 (see Web Appendix A.3).

Participants over the age of 18 were recruited through a large-scale online panel run by a marketing research company in the Netherlands. A total of 1,577 valid responses were obtained. The average age of the participants in the sample was 45.5 years old, $51.1 \%$ of the, were female, $42.2 \%$ had obtained a bachelor's or higher degree, and $45.3 \%$ had bought health insurance for themselves or for someone else in their household in the past two years. 


\section{Results}

As in Study 1, we tested the effect of ordering and partitioning using as a dependent variable whether or not participants selected the objectively best product in each condition, and a second, complementary dependent variable, how much a participant overpaid compared to the best insurance product by selecting a suboptimal alternative. ${ }^{3}$ Both dependent measures show a similar pattern, seen in Figure 4, panel B. The partially informed ordering is less effective than the fully informed ordering, but much closer to the informed than to the naïve ordering. Most importantly, the effect of ordering interacts with partitioning: Partitioning helps with informed or partially informed ordering but hurts for a naïve ordering. Many participants selected the best alternative in the partially informed ordering condition (though fewer than in the informed condition) and partitioning helped with both fully informed and partially informed orders. The figure shows that the informed and intermediate ordering clearly made a difference, with a naïve ordering producing worse performance in both outcome measures

We tested this pattern using a logistic regression analysis that modeled the probability of participants' selection of the best product, using the effects of ordering, partitioning, and their interaction. The ordering was represented as an indicator variable, with naïve ordering being the base level. Partitioning was also represented as an indicator variable, with non-partitioning as the base level. The results confirm the impression given by the figure and our hypotheses. We find a positive effect of informed ordering but not partial ordering in the non-partitioned condition $\left(\beta_{\text {INFORMED }}=.44, p=.01 ; \beta_{\text {PARTIAL }}=.10\right.$, n.s. $)$. There is a negative effect of partitioning

\footnotetext{
${ }^{3}$ We obtained this measure by first calculating the ratio of the monthly premium and the customer review rating for each product (in accordance with the participants' task). Using this ratio, we calculated a virtual yearly price for each consumers' selected product at the consumer review score of the best available product. The difference between this virtual price and the actual price for the best available product was the amount a consumer overpaid.
} 
in the naïve ordering condition $\left(\beta_{\text {PARTITION }}=-2.67, p<.001\right)$, but this is more than compensated for in the informed and partially informed conditions by the large and significant interaction effect $\left(\beta_{\text {INFORMED }{ }^{*} \text { PARTITION }}=2.94, p<.001 ; \beta_{\text {PARTIAL }}{ }^{*}\right.$ PARTITION $\left.=3.05, p<.001\right)$. Jointly, these results provides strong support for $\mathrm{H} 4$, and show that in the partially informed condition there is also a positive effect of partitioning, in line with what we observed in Study 3 . We also ran an analysis controlling for participants' experience with buying health insurance in the past two years (yes/no). While prior experience helped $(\beta=.24, p=.03)$, it did not affect the significance of the other results.

Testing the amount overpaid showed a similar pattern of significance. An analysis of variance looking at the three levels of ordering and the two partitioning levels and their interactions strongly support the hypothesized effects. There is a strong significant effect of ordering in the predicted direction $(\mathrm{F}(2,1571)=69.7, p<.001)$, with lower losses in the case of higher user model quality. We find an negative effect of partitioning $(\mathrm{F}(1,1571)=6.6$, $p=.01)$, which is compensated for by the hypothesized large interaction effect of ordering and partitioning $(\mathrm{F}(2,1571)=44.2 ; p<.001)$. This interaction reflects the detrimental effect of partitioning in the naïve ordering condition, which, in the main effect, dominates the positive impact of ordering in the informed and partially informed conditions. Additional analysis of the simple effects of partitioning within each ordering condition reveals the significance of these contrasting effects per condition and in the expected direction. As hypothesized, we find that the impact of partitioning is significantly positive in the informed and partially informed ordering conditions ( $p=.03$ and $p=.02$, respectively), but significantly negative in the naïve ordering condition $(p<.001)$. Again, we also conducted analysis of variance while controlling for participants' experience with buying health insurance. The effect of this control variable was not 
significant and adding it to the model did not affect the significance of the other results.

\section{Discussion}

The results of Study 4 provide further support for the hypothesized moderating effect of ordering on the impact of partitioning on consumer choice outcomes in a normative setting with objectively different quality levels between different choice outcomes. The outcome of our analyses strongly support the hypothesized effects of ordering and partitioning on consumer choice outcomes. We find that, with informed and partially informed ordering, partitioning is beneficial for consumers, but with naïve ordering, partitioning is not beneficial and can even be harmful to consumer choice outcomes.

\section{General Discussion}

The results from all four studies show that as we hypothesized, ordering and partitioning have a significant and beneficial impact on consumer choice outcomes, but that these effects depend upon having a good user model. Consumers are more likely to choose the best alternative when presented with a set that is ordered according to overall product attractiveness and partitioned into a small recommended set with the possibility of clicking through to see the full set. We show that this is because the partition encourages the use of a compensatory decision strategy and when combined with an informed ordering, focuses consumer attention on a small set of high quality options.

Since we are interested in improving the choice of health care policies, we can look at the performance of the incentivized decision-maker in Study 1. In that study, consumers made mistakes in excess of $\$ 865$ dollars when presented with the least effective choice architecture. 
Having an informed order reduced that error to about $\$ 295$, but adding a partition to that ordering reduced errors to just over $\$ 122$, a savings of about $\$ 743$ per decision-maker. While these figures are specific to this study, they are similar to the size of errors reported in earlier framed-field experiments (Johnson et al. 2013) and field studies (Bhargava et al. 2017). Given that there are slightly over 200 million people covered by private plans and 100 million by government plans, many of which involve choice, the stakes of getting the choice architecture right could be measured in billions, if not trillions of dollars in the U.S. alone.

\section{Theoretical Implications}

In addition to our proposition that decision focus and strategy selection are important mediators of choice architecture effects, we contribute two additional, broader theoretical considerations. First, our research makes explicit a notion long implicit in the choice architecture literature: the idea of a user model. If choice architects have a high-quality user model, they can intervene more effectively, since they can identify what is the correct option for each decision maker. While we talk about this impact in terms of ordering and partition, it is also relevant in other choice architecture interventions such as defaults (Johnson and Goldstein 2003).

Second, our study suggests that the effects of choice architecture tools depend on the context and presence of other choice architecture tools. In the present studies, partitioning and ordering did not simply have additive effects, but rather interactive effects. In fact, partitioning had a positive impact on choices when options were ordered in an informed fashion, but a negative impact when options were naively ordered. This suggests that choice architecture tools should be evaluated as ensembles and consumers could react differently to ensembles than to 
each tool individually. Contemporary websites often allow the user to employ multiple tools. Airline sites allow consumers to screen their options (e.g., by time, airline), a specific case of partitioning, and provide ordering options (e.g., by fare). Our notion of ensembles suggests that, although each could usually be helpful, there are conditions under which they can lead to worse choice outcomes, particularly when one is applied with a poor implementation of the other. Obviously, both of these implications merit further inquiry.

\section{Future Research}

Ordering and partitioning, their interaction, and the idea of user models all raise important questions for future research and application. Obviously, the idea of developing algorithms and models to make recommendations is a growing and vibrant area of consumer research (Chintagunta et al. 2016). We hope that such models not only produce better quality predictions but are increasingly able to model the heterogeneity in consumer preferences. Such heterogeneity in preferences has been a challenge for the use of choice architecture. Defaults, for example, have usually been applied as a 'one size fits all' framework. Yet it is possible to customize choice architecture, say through the use of customized 'smart defaults' to embrace such heterogeneity (Goldstein et al. 2008).

An important question is how to improve decisions when user models make weak predictions. One idea would be to adjust the characteristics of the presentation to reflect uncertainty in what people want. Partitioning offers a good example. If the firm is very certain of the quality of its user model, then the partitioned set can be quite small. With greater uncertainty, the size of the partitioned set can increase until, at the extreme, there would be no 
partitioning at all. There is, therefore, no "one size fits all," optimal partitioning size; rather, there are different optimal sizes for different markets and different firm modelling capabilities.

\section{Managerial and Policy Implications}

We close by discussing the tension we mentioned in the opening of the article, potentially between the interests of consumers and the profit-maximizing interests of firms. We began by suggesting that there are situations where firms may know what is in the best interest of consumers and can prevent them from making mistakes. We have examined one domain, namely health insurance, where that is arguably true. Firms may have, for example, a more accurate idea of someone's risks than the individual him- or herself because dangerous health events are both rare and potentially catastrophic. We doubt that the average purchaser has an accurate view of the probability and cost of an auto accident or of contracting a serious disease when making a health insurance purchase.

Firms may, in the short term, exploit these informational asymmetries, but the current work suggests another path, to build choice architectures that will help consumers make better decisions. The success of this strategy may depend upon the ability of firms to convince people that there is value in following their recommendations, and this is likely to be a long-term proposition. However, there are examples where firms have seemed to take this approach. In investments, Betterment, a so-called robo-advisor, has prospered increasing assets under management to $\$ 16$ billion dollars since its founding in 2010. A major value proposition has been delivering a solution to "bad" behavior by consumers, for example improving their decisions by prioritizing the display of long-term returns to consumers and by explaining to them 
why they should not sell in short term markets. Other solutions are automated investment strategies, such as rebalancing portfolios automatically.

\section{Conclusion}

In close, it is worth noting that there are two factors that may affect our view of the marketing function in relation to choice architecture. The first is the advent of a deeper understanding of the errors that can be made by consumers. While some deviations from rationality may be defensible, others, such as paying too much for a dominated health insurance policy, or not investing properly for retirement, are harder to rationalize, and are probably significant mistakes that have negative financial and welfare effects. The second is that given the advent of big data, firms may be better able to suggest choices that lead consumers to more satisfying outcomes than consumers themselves are. Together, these factors suggest a marketing opportunity that is not apparent in models that posit a more rational, fully informed decisionmaker. Choice architecture, wisely applied, can be a relatively inexpensive and efficient way to use this knowledge to improve social welfare. Both better prediction of consumer choices and choice architecture could be used to increase short term profit. For example, an insurer who observes their consumers paying too much for a dominated policy might be pleased with the increased revenue. However, we hope that firms use this knowledge to develop new business models that deliver longer term value to both consumers and their stockholders. 


\section{References}

Atalay, A Selin, H. Onur Bodur, and Dina Rasolofoarison (2012), "Shining in the Center:

Central Gaze Cascade Effect on Product Choice," Journal of Consumer Research, 39(4), $848-66$.

Bar-Hillel, Maya (2015), "Position Effects in Choice From Simultaneous Displays: A Conundrum Solved," Perspectives on Psychological Science, 10(4), 419-433.

Besedeš, Tibor, Cary Deck, Sudipta Sarangi, and Mikhael Shor (2015), "Reducing Choice Overload without Reducing Choices," Review of Economics and Statistics, 97(4), 793802.

Bettman, James R., Eric J. Johnson, Mary F. Luce, and John W. Payne (1993), “Correlation, Conflict, and Choice," Journal of Experimental Psychology: Learning, Memory, and Cognition, 19(4), 931-951.

Bhargava, Saurabh, George Loewenstein, and Justin Sydnor (2017), "Choose to Lose: Health Plan Choices from a Menu with Dominated Options," Quarterly Journal of Economics, 132(3), 1319-1372.

Brown, Christina L., and Aradhna Krishna (2004), "The Skeptical Shopper: A Metacognitive Account for the Effects of Default Options on Choice," Journal of Consumer Research, 31 (3), 529-539.

Cadario, Romain, and Pierre Chandon (2018), “Which Healthy Eating Nudges Work Best? A Meta-Analysis of Field Experiments," Marketing Science, (forthcoming).

Carroll, Gabriel D., James J. Choi, David Laibson, Brigitte C. Madrian, and Andrew Metrick (2009), “Optimal Defaults and Active Decisions,” Quarterly Journal of Economics, 
124(4), 1639-74.

Chakravarti, Amitav, Chris Janiszewski, and Gülden Ülkümen (2006), “The Neglect of

Prescreening Information,” Journal of Marketing Research, 43(4), 642-653.

Cheema, Amar, and Dilip Soman (2008), "The Effect of Partitions on Controlling

Consumption," Journal of Marketing Research, 45(6), 665-75.

Chernev, Alexander, Ulf Böckenholt, and Joseph Goodman (2015), "Choice Overload: A Conceptual Review and Meta-Analysis," Journal of Consumer Psychology, 25(2), 333358.

Chintagunta, Pradeep, Dominique M. Hanssens, and John R. Hauser (2016), "Marketing Science and Big Data," Marketing Science, 35(3), 341-342.

Costa-Gomes, Miguel A., and Vincent P. Crawford (2006), "Cognition and Behavior in TwoPerson Guessing Games: An Experimental Study,” American Economic Review, 96(5), $1737-68$.

Dellaert, Benedict G.C., and Gerald Häubl (2012), "Searching in Choice Mode: Consumer Decision Processes in Product Search with Recommendations," Journal of Marketing Research, 49(2), 277-288.

Diehl, Kristin (2005), "When Two Rights Make a Wrong: Searching too Much in Ordered Environments," Journal of Marketing Research, 42(3), 313-322.

Dinner, Isaac, Eric J. Johnson, Daniel G. Goldstein, and Kaiya Liu (2011), "Partitioning Default Effects: Why People Choose not to Choose," Journal of Experimental Psychology: Applied, 17 (4), 332-41.

Dorn, Michael, Claude Messner, and Michaela Wänke (2016), "Partitioning the Choice Task Makes Starbucks Coffee Taste Better," Journal of Marketing Behavior, 1(3-4), 363-384. 
Ericson, Keith Marzilli, and Amanda Starc (2012), "Heuristics and Heterogeneity in Health Insurance Exchanges: Evidence from the Massachusetts Connector," American Economic Review, 102(3), 493-497.

Feenberg, Daniel, Ina Ganguli, Patrick Gaule, and Jonathan Gruber (2017), "It's Good to Be First: Order Bias in Reading and Citing NBER Working Papers," Review of Economics and Statistics, 99(1), 32-39

Gabaix, Xavier, David Laibson, Guillermo Moloche, and Stephen Weinberg (2006), “Costly Information Acquisition: Experimental Analysis of a Boundedly Rational Model,” American Economic Review, 96(4), 1043-1068.

Gilbride, Timothy J., and Greg M. Allenby (2004), “A Choice Model with Conjunctive, Disjunctive, and Compensatory Screening Rules," Marketing Science, 23(3), 391-406.

Goldstein, Daniel G., Eric J. Johnson, Andreas Herrmann, and Mark Heitmann (2008), “Nudge Your Customers Toward Better Choices," Harvard Business Review, 86(12), 99-105.

Hanoch, Yaniv, Stacy Wood, Andrew Barnes, Pi-Ju Liu, and Thomas Rice (2011), “Choosing the Right Medicare Prescription Drug Plan: The Effect of Age, Strategy Selection, and Choice Set Size," Health Psychology, 30(6), 719-727.

Harrison, Glenn W., and John A. List (2004), “Field Experiments," Journal of Economic Literature, 42(4), 1009-1055.

Häubl, Gerald, Benedict G.C. Dellaert, and Bas Donkers (2010), “Tunnel Vision: Local Behavioral Influences on Consumer Decisions in Product Search," Marketing Science, 29(3), 438-455.

Hayes, Andrew F. (2013), Introduction to Mediation, Moderation, and Conditional Process Analysis: A Regression-Based Approach, Guilford Press. 
Ho, Daniel E., and Kosuke Imai (2008), "Estimating Causal Effects of Ballot Order from a Randomized Natural Experiment: The California Alphabet Lottery, 1978-2002,” Public Opinion Quarterly, 72(2), 216-240.

Hogarth, Robin M., and Hillel J. Einhorn (1992), “Order Effects in Belief Updating: The BeliefAdjustment Model," Cognitive Psychology, 24(1), 1-55.

Jachimowicz, Jon M., Shannon Duncan, Elke U. Weber, and Eric J. Johnson (2017), “When and Why Defaults Influence Decisions: A Meta-Analysis of Default Effects," Behavioural Public Policy, 1-28.

Johnson, Eric J., and Daniel Goldstein (2003), “Do Defaults Save Lives?” Science, 302 (2003), 1338-1339.

Johnson, Eric J., Ran Hassin, Tom Baker, Allison T. Bajger, and Galen Treuer (2013), “Can Consumers Make Affordable Care Affordable? The Value of Choice Architecture," PLoS ONE, 8(12), e81521, doi:10.2139/ssrn.2291598.

Johnson, Eric J., and Robert J. Meyer (1984), “Compensatory Choice Models of Noncompensatory Processes: The Effect of Varying Context," Journal of Consumer Research, 11(1), 528-541.

Johnson, Eric J., and John W. Payne (1985), “Effort and Accuracy in Choice," Management Science, 31(4), 395-414.

Johnson, Eric J., Suzanne B. Shu, Benedict G.C. Dellaert, Craig Fox, Daniel G. Goldstein, Gerald Häubl, Richard P. Larrick, John W. Payne, Ellen Peters, David Schkade, Brian Wansink, and Elke U. Weber (2012), "Beyond Nudges: Tools of a Choice Architecture," Marketing Letters, 23(2), 487-504.

Koppell, Jonathan G.S., and Jennifer A. Steen (2004), “The Effects of Ballot Position on 
Election Outcomes," Journal of Politics, 66(1), 267-281.

Lamberton, Cait Poynor, and Kristin Diehl (2013), "Retail Choice Architecture: The Effects of Benefit- and Attribute-Based Assortment Organization on Consumer Perceptions and Choice," Journal of Consumer Research, 40(3), 393-411.

Loewenstein, George, Joelle Y. Friedman, Barbara McGill, Sarah Ahmad, Suzanne Linck, Stacey Sinkula, John Beshears, James J. Choi, Jonathan Kolstad, David Laibson, Brigitte C. Madrian, John A. List, and Kevin G. Volpp (2013), “Consumers' Misunderstanding of Health Insurance," Journal of Health Economics, 32(5), 850-62.

Lohse, Gerald L., and Eric J. Johnson (1996), “A Comparison of Two Process Tracing Methods for Choice Tasks," Organizational Behavior and Human Decision Processes, 68(1), 28 43.

Lynch, John G., and Dan Ariely (2000), "Wine Online: Search Costs Affect Competition on Price, Quality, and Distribution," Marketing Science, 19(1), 83-103.

Madrian, Brigitte C., Hal E. Hershfield, Abigail B. Sussman, Saurabh Bhargava, Jeremy Burke, Scott A. Huettel, Julian Jamison, Eric J. Johnson, John G. Lynch, Stephan Meier, Scott Rick, and Suzanne B. Shu (2017), "Behaviorally Informed Policies for Household Financial Decisionmaking," Behavioral Science \& Policy, 3(1), 26-40.

Mantonakis, Antonia, Pauline Rodero, Isabelle Lesschaeve, and Reid Hastie (2009), "Order in Choice: Effects of Serial Position on Preferences," Psychological Science, 20(11), 13091312.

Milkman, Katherine L., Julia A. Minson, and Kevin G.M. Volpp (2013), "Holding the Hunger Games Hostage at the Gym: An Evaluation of Temptation Bundling," Management Science, 60(2), 283-299. 
Miller, Joanne M., and Jon A. Krosnick (1998), “The Impact of Candidate Name Order on Election Outcomes," Public Opinion Quarterly, 62(3), 291-330.

Payne, John W. (1976), “Task Complexity and Contingent Processing in Decision Making: An Information Search and Protocol Analysis," Organizational Behavior and Human Performance, 16(2), 366-387.

Payne, John W., James R. Bettman, and Eric J. Johnson (1993), The Adaptive Decision Maker, Cambridge, England: Cambridge University Press.

Reisen, Nils, Ulrich Hoffrage, and Fred W. Mast (2008), “Identifying Decision Strategies in a Consumer Choice Situation," Judgment and Decision Making, 3(8), 641.

Russo, J. Edward, Kurt A. Carlson, and Margaret G. Meloy (2006), “Choosing an Inferior Alternative," Psychological Science, 17(10), 899-904.

Suk, Kwanho, Jiheon Lee, and Donald R. Lichtenstein (2012), “The influence of Price Presentation Order on Consumer Choice," Journal of Marketing Research, 49(5), 708717.

Szaszi, Barnabas, Anna Palinkas, Bence Palfi, Aba Szollosi, and Balazs Aczel (2018), “A Systematic Scoping Review of the Choice Architecture Movement: Toward Understanding When and Why Nudges Work," Journal of Behavioral Decision Making, $31(3), 355-366$

Thaler, Richard H., and Schlomo Benartzi (2004), "Save More Tomorrow ${ }^{\text {TM}}$ : Using Behavioral Economics to Increase Employee Saving, ”Journal of Political Economy, 112(S1), S164S187.

Thaler, Richard H., and Cass R. Sunstein (2008), Nudge, New Haven, CT: Yale University Press. Ubel, Peter A, David A Comerford, and Eric Johnson (2015), "Healthcare.gov 3.0--Behavioral 
Economics and Insurance Exchanges,” The New England Journal of Medicine, 372(8), 695-98.

Willemsen, Martijn C., and Eric J. Johnson (2011), “Visiting the Decision Factory: Observing Cognition with MouselabWEB and Other Information Acquisition Methods,” In SchulteMecklenbeck, M., Kühberger, A., and Ranyard, R. (Eds.), A Handbook of Process Tracing Methods for Decision Making (pp. 21-42), New York: Taylor \& Francis.

Wilson, Timothy D., Thalia Wheatley, Jonathan M. Meyers, Daniel T. Gilbert, and Danny Axsom (2000), "Focalism: A Source of Durability Bias in Affective Forecasting," Journal of Personality and Social Psychology, 78(5), 821-836.

Wong, Charlene A., Arthur T. Jones, Janet Weiner, Robert J. Town, and Tom Baker (2016), “For Third Enrollment Period, Marketplaces Expand Decision Support Tools to Assist Consumers," Health Affairs, 35(4), 680-687.

Woolhandler, Steffie, and David U. Himmelstein (2017), “The Relationship of Health Insurance and Mortality: Is Lack of Insurance Deadly?” Annals of Internal Medicine, 167(6), 424431.

Zhao, Xinshu, John G. Lynch, and Qimei Chen (2010), "Reconsidering Baron and Kenny: Myths and Truths about Mediation Analysis," Journal of Consumer Research, 37(2), 197-206. 


\section{Table 1}

Study 1: Mediation Analysis for Best Choice ${ }^{\S}$

\begin{tabular}{|c|c|c|}
\hline Unstandardized Regression Coefficients of the Model Pathways & $\begin{array}{l}\text { Parameter } \\
\text { estimate }\end{array}$ & t-value \\
\hline Partitioning on Decision Strategy (H1) & $.04^{* *}$ & 4.44 \\
\hline Informed Ordering on Decision Strategy & $-.02^{* *}$ & -2.13 \\
\hline Interaction of Informed Ordering and Partitioning on Decision Strategy & .01 & .58 \\
\hline Partitioning on Decision Focus & $-1.41^{* *}$ & -24.94 \\
\hline Informed Ordering on Decision Focus (H2) & $1.82^{* *}$ & 32.22 \\
\hline Interaction of Informed Ordering and Partitioning on Decision Focus (H3) & $1.66^{* *}$ & 29.24 \\
\hline Decision Strategy on Choice of Best Alternative & $.82^{* *}$ & 4.96 \\
\hline Decision Focus on Choice of Best Alternative & $.69^{* *}$ & 7.70 \\
\hline Partitioning on Choice of Best Alternative & .02 & .37 \\
\hline Informed Ordering on Choice of Best Alternative & -.14 & -1.86 \\
\hline $\begin{array}{l}\text { Interaction of Informed Ordering and Partitioning on Choice of Best } \\
\text { Alternative }\end{array}$ & -.07 & -1.11 \\
\hline Bootstrap Tests of Indirect (Mediated Moderation) Effects (H5) & Effect & S.E. \\
\hline Indirect Effect of Decision Strategy (Naïve Ordering) & $.03^{*}$ & .01 \\
\hline 5,000 bootstraps C.I. at $95 \%$ & $L L=.01$ & $U L=.06$ \\
\hline Indirect Effect of Decision Strategy (Informed Ordering) & $.04^{*}$ & .01 \\
\hline 5,000 bootstraps C.I. at $95 \%$ & $L L=.02$ & $U L=.07$ \\
\hline Indirect Effect of Decision Focus (Naïve Ordering) & $-2.10^{*}$ & .20 \\
\hline 5,000 bootstraps C.I. at $95 \%$ & $L L=-2.54$ & $U L=-1.78$ \\
\hline Indirect Effect of Decision Focus (Informed Ordering) & $.17^{*}$ & .02 \\
\hline 5,000 bootstraps C.I. at $95 \%$ & $L L=.13$ & $U L=.21$ \\
\hline $\begin{array}{l}\text { Moderating Effect of Informed Ordering on Indirect Effect of Decision } \\
\text { Strategy }\end{array}$ & .01 & .02 \\
\hline 5,000 Bootstraps C.I. at $95 \%$ & $\mathrm{LL}=-.02$ & $U L=.04$ \\
\hline $\begin{array}{l}\text { Moderating Effect of Informed Ordering on Indirect Effect of Decision } \\
\text { Focus }\end{array}$ & $2.27^{*}$ & .21 \\
\hline 5,000 bootstraps C.I. at $95 \%$ & $\mathrm{LL}=1.92$ & $U L=2.73$ \\
\hline
\end{tabular}

\footnotetext{
$\S$ We also include a choice task order variable in the model that captures the average difference between the first and second sets of choices for each respondent. For expositional clarity, this variable is not tabulated. While the PROCESS module we used for estimation does not allow for random effects, we also ran the analysis for only the first choice for each participant and obtained similar findings. In this table, $\mathrm{n}=828$ (with two choice tasks observed for most but not all respondents). The superscripts ** and *, respectively, denote significance at $p<.01$ and $p<.05$.
} 
Figure 1

Hypothesized Mediated Moderation Structure ${ }^{\mathfrak{t}}$

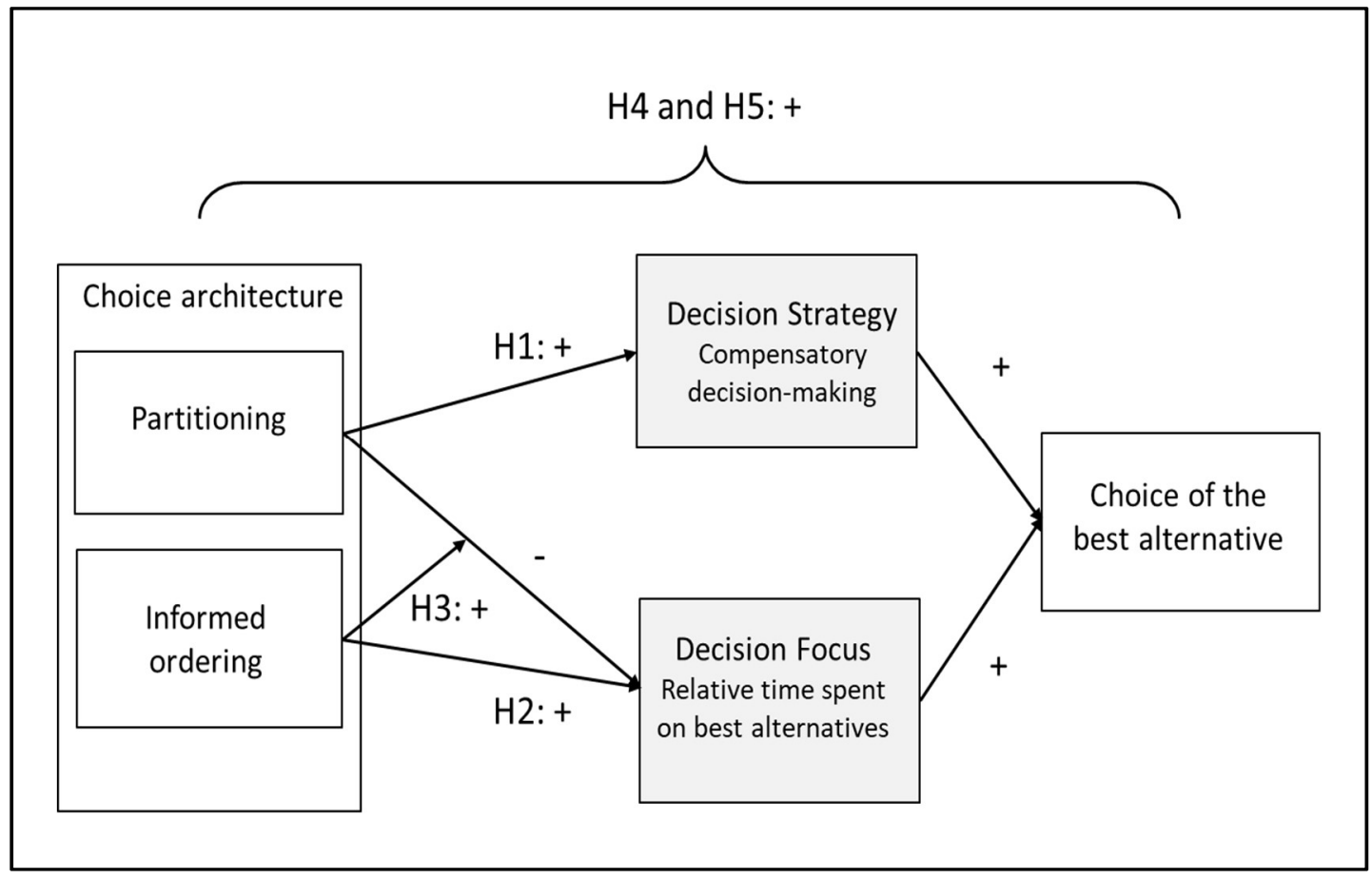

$£$ The moderating effect of informed ordering on the relationship between partitioning and decision focus is indicated by an arrow impacting the path from partitioning to decision focus. Informed ordering results in a positive effect of partitioning on decision focus and choice of the best alternative. However, naïve ordering reverses the effect of partitioning and leads to lower decision focus and lower decision quality. 
Figure 2

Study 1: Process Data MouselabWEB

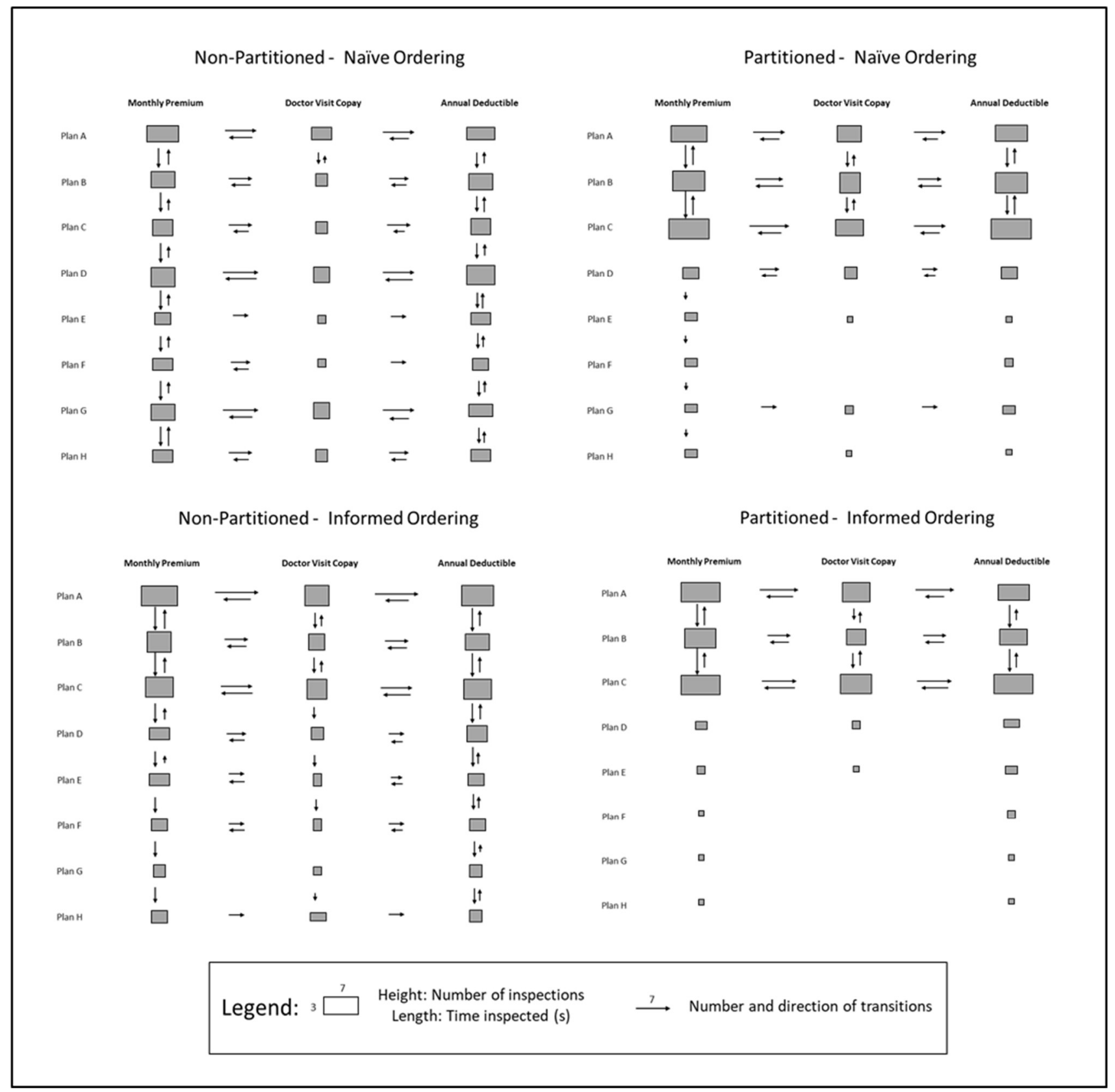


Figure 3

Study 1: Decision Process Measures ${ }^{\mathfrak{t}}$

\section{Panel A - Decision strategy: Payne Index ${ }^{\S}$}

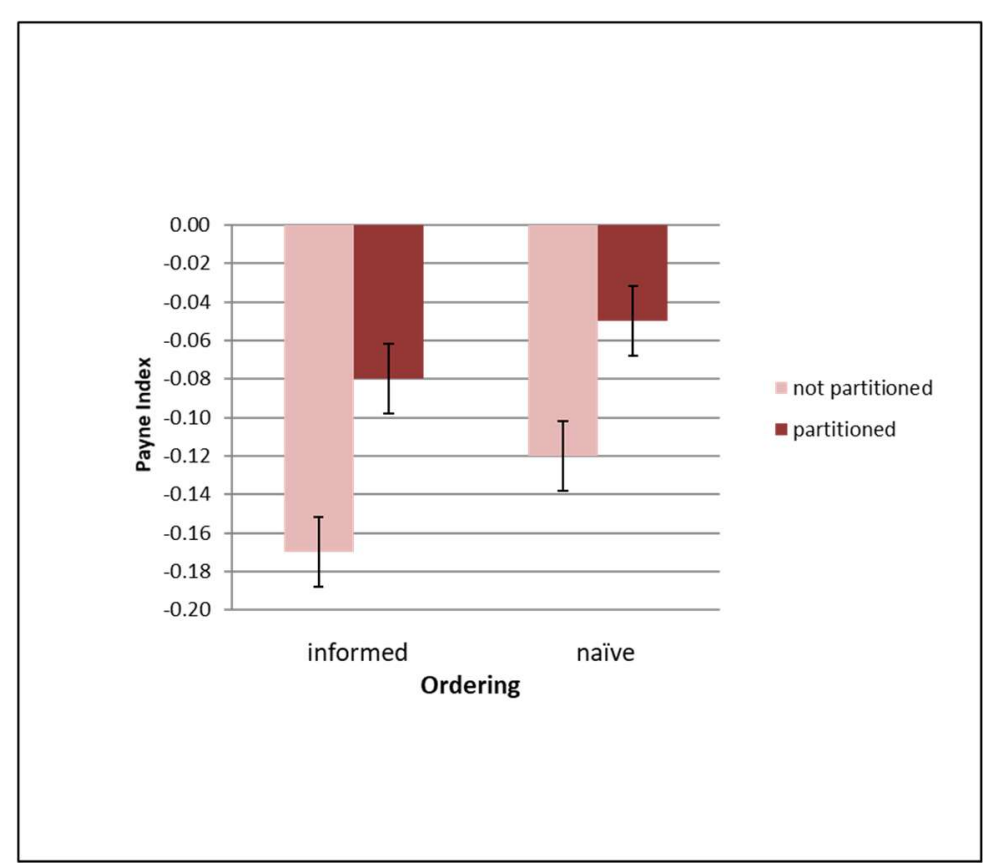

$£$ Lines in bars represent standard errors.

$\S$ For the Payne Index, higher (less negative) scores imply a more compensatory decision process.
Panel B - Decision focus:

Ratio of time spent on best three options

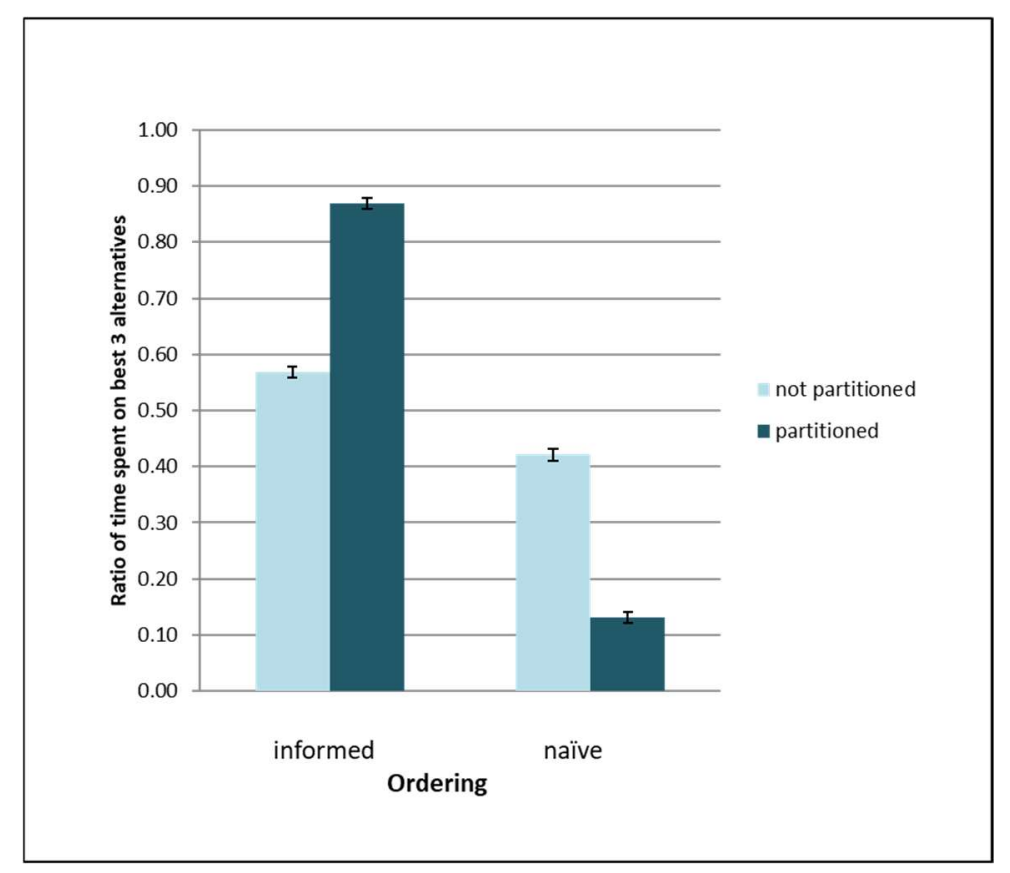


Figure 4

Percentage of Accurate Consumer Choices and Yearly Amount Overpaid Due to Not Choosing the Best Product ${ }^{\mathfrak{f}}$

Panel A - (Study 1)

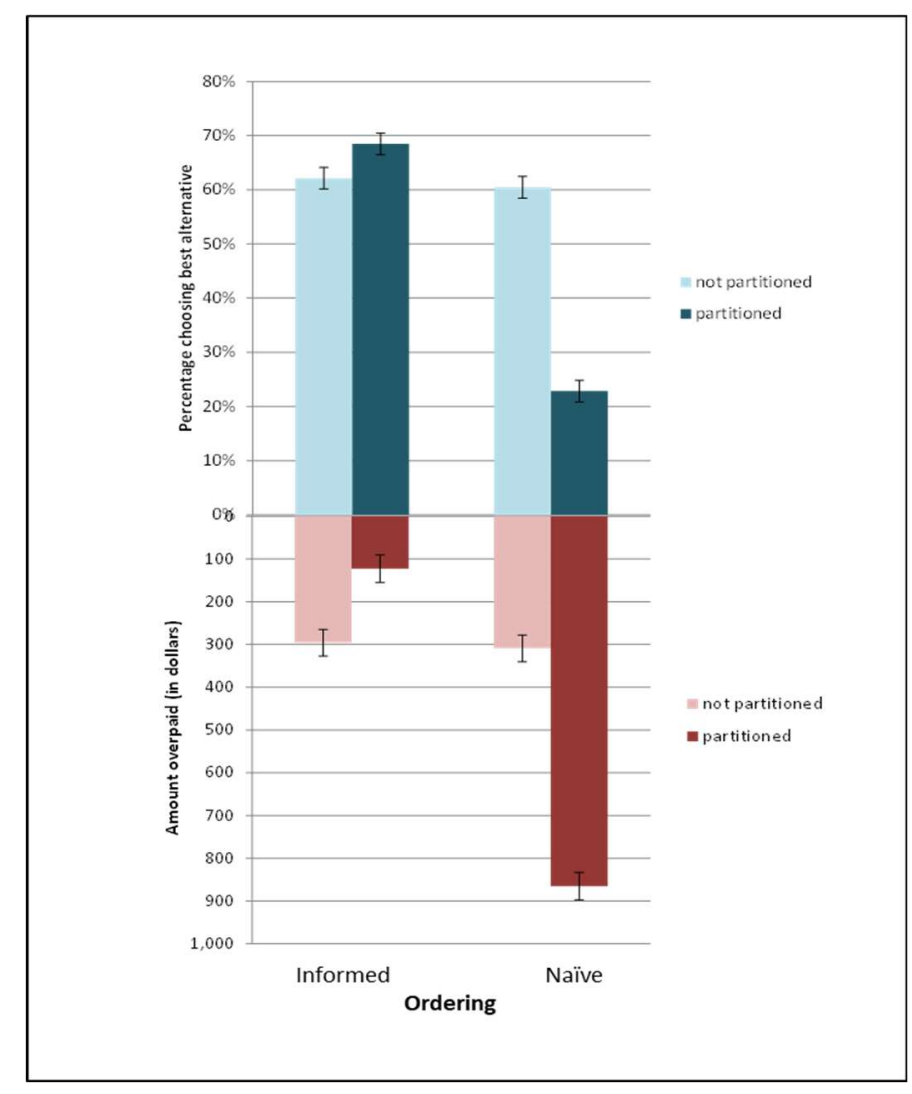

Panel B - (Study 4)

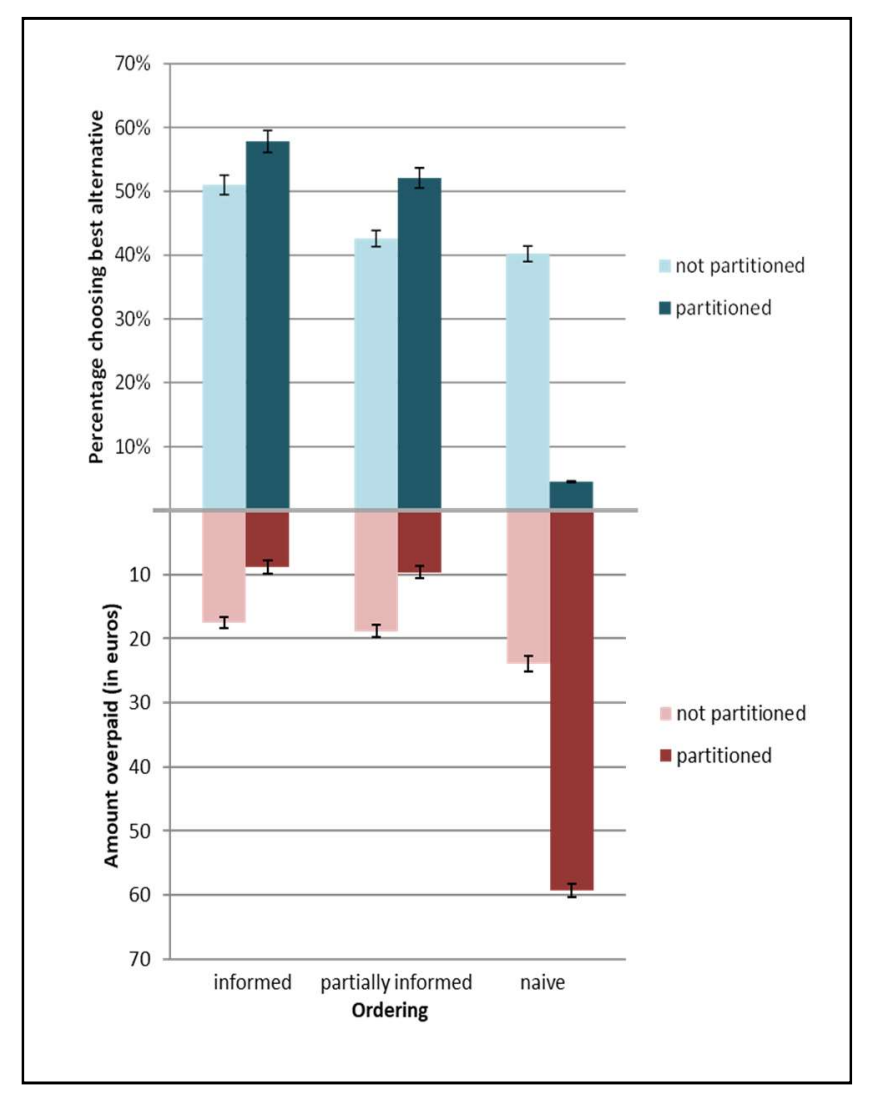

$£$ Lines in bars represent standard errors. 
Figure 5

Field Study: Consumer Choices Before and After the Introduction of Informed Ordering and Partitioning

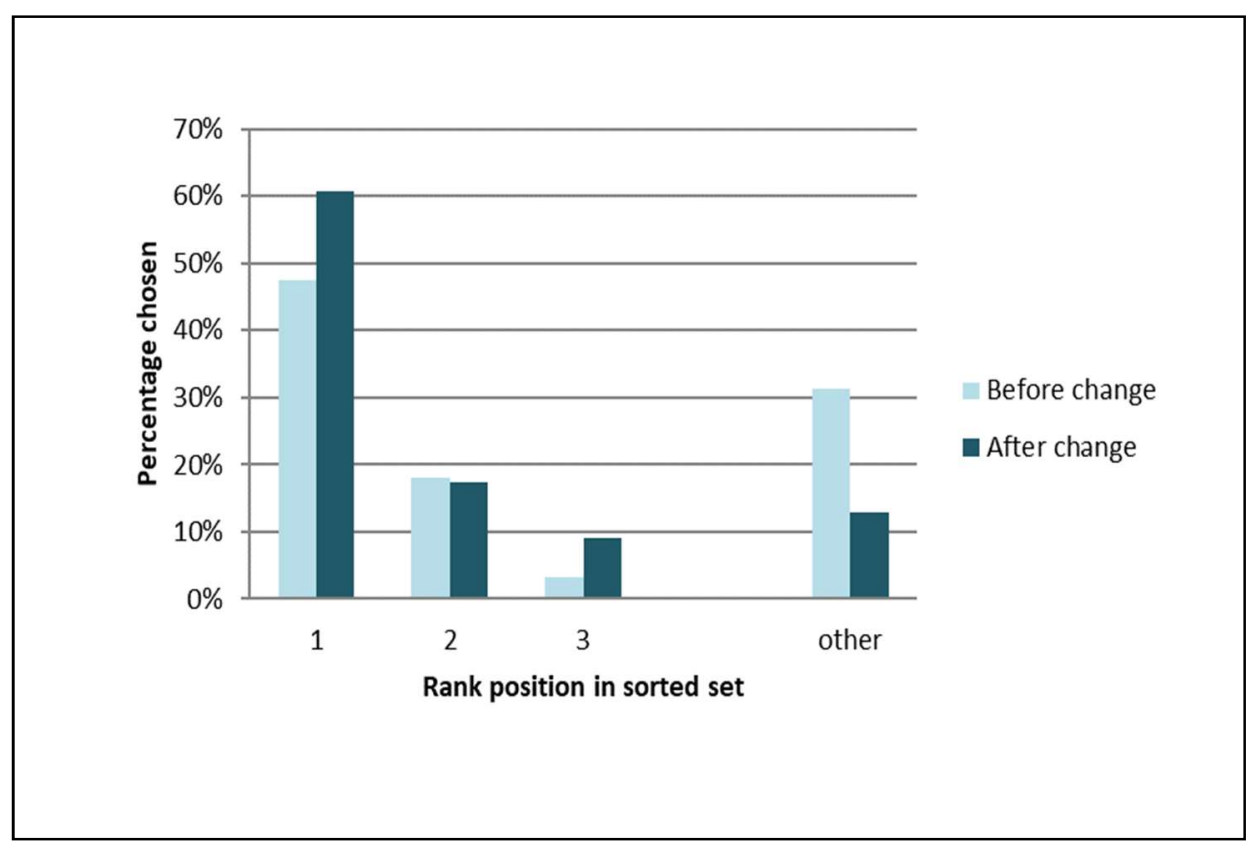

